\title{
CLARICE LISPECTOR Y LA TEORÍA DE LOS AFECTOS UNA LECTURA SOBRE LA PASIÓN SEGÚN G.H.
}

\author{
Valerie Osorio Restrepo ${ }^{1}$
}

\begin{abstract}
Resumen
La novela La pasión según G.H. puede leerse como un antecedente de la teoría de los afectos en América Latina. Ya en los años 60, Clarice Lispector estaba planteando asuntos que la academia ha estudiado con el nombre de giro afectivo (affective turn): la cuestión de las emociones como indicadores históricos, la diferencia entre afecto y emoción, la materialidad y la vitalidad, la división entre emoción y razón, y la relación con lo no humano.
\end{abstract}

Palabras clave

Teoría de los afectos. Intimidad. Subjetividad. Lispector.

"Ayer, sin embargo, perdí durante horas mi montaje humano" (LISPECTOR, 2001, p.12). Escrita en primera persona, La pasión según G.H. (1964) narra la introspección en la que G.H. se hace la pregunta sobre qué significa ser una persona. Después de la renuncia de Janair, su empleada doméstica, G.H. decide quedarse en su casa para reorganizar el cuarto de la empleada, que presume sucio. Su primer impacto ocurre cuando lo encuentra limpio y ve en la pared una silueta de un hombre, una mujer y un perro, dibujados por Janair. El segundo impacto ocurre cuando se encuentra frente a frente (el resaltado es importante porque quiero indicar horizontalidad) a una cucaracha, y las reflexiones sobre su humanidad continúan. Si bien está sola en su apartamento, siente la necesidad de crear un interlocutor para ir haciéndolo partícipe de sus introspecciones.

Empiezo con la referencia al montaje humano, porque me conduce directamente a la lectura que quiero proponer sobre la relación entre Clarice Lispector (1920-1977) y la teoría de los afectos en América Latina. En los años 90, la academia norteamericana hizo un giro

\footnotetext{
${ }^{1}$ Candidata a doctora del programa Iberian and Latin American Languages and Cultures, en la Universidad de Texas, en Austin. Egresada de la carrera de Literatura, la Maestría en Educación y la Maestría en Literatura de la Pontificia Universidad Javeriana, en Bogotá, Colombia. Ha publicado artículos en Cuadernos de literatura (Universidad Javeriana), Latin American Literary Review y, próximamente, en Perífrasis (Universidad de los Andes, Colombia).
} 
hacia los afectos (affective turn) para señalar "un dinamismo inmanente a la materia corporal y la materia en general" (CLOUGH, 2010, p.207, traducción mía). Dentro de sus preocupaciones, está la consideración general de la capacidad de los cuerpos de afectar y ser afectados, la relación con lo no humano, la relación política entre las esferas pública, privada e íntima - heredada del feminismo-, la consideración del afecto como una fuerza preindividual o como sinónimo de las emociones y la problematización de "la relación entre mente y cuerpo, acciones y pasiones, razón y emociones, pensamiento y acción”. (DEL SARTO, 2012, p.49)

En el contexto latinoamericano, "el campo de estudios de los afectos y las emociones se viene institucionalizando a partir de la conformación de redes y de la organización de coloquios, simposios y seminarios" (ABRAMOWSKI y CANEVARO, 2017, p.10). En el ensayo Los afectos en los estudios culturales latinoamericanos: Cuerpos y subjetividades en Ciudad Juárez, Ana del Sarto hace una genealogía de la teoría de los afectos en la academia anglosajona y explica que "el boom de los afectos en la academia estadounidense, sobre todo su enfoque y su léxico, responde en la superficie al impacto que las nuevas tecnologías tienen en relación con la comprensión del ser humano y con la posibilidad de que este se piense a sí mismo en su ambiente" (2012, p. 50). Para hablar de la presencia de la teoría de los afectos en América Latina, menciona los conceptos de Jesús Martín Barbero, tales como "sensorium popular", "mapa nocturno" y "memoria cultural”; el trabajo de Beatriz Sarlo, El imperio de los sentimientos; y las subjetividades construidas en la obra de Carlos Monsiváis (ibid, p. 51).

Sobre la base de las preguntas por la comprensión del ser humano, sus autorreflexiones, la preocupación por lo material corporal/vital y teniendo en cuenta la trayectoria introspectiva de G.H., sostengo que Clarice Lispector es un antecedente de la teoría de los afectos en América Latina. En su obra se plantea la pregunta sobre qué significa ser y vuelve al cuerpo como elemento que contiene la vida y que puede montarse y desmontarse para comprender qué es lo vital, dónde mora lo humano, cómo nos relacionamos con otras formas de vida, cuáles son los atributos de los que podemos despojarnos, cuál es la diferencia entre la mirada pública hacia el cuerpo que somos y la mirada privada que el sujeto hace sobre sí mismo, de qué manera las emociones - como el dolor, por ejemplo- dan cuenta de lo que somos. (Cabe aclarar, sin embargo, que esta tesis no pretende dotar la literatura de Lispector de carácter fundacional de una teoría que está lejos de ser homogénea). 
La literatura de Lispector es, en sí misma, un giro: irrumpe con Cerca del corazón salvaje (1944) en el panorama de las letras brasileñas en un momento en que la tendencia dominante se caracterizaba por enfocar la mirada hacia el país, especialmente sus problemas sociales con un notorio énfasis en la región del sertón nordestino. Entre 1930 y 1945, primó una literatura regionalista o con orientaciones hacia lo social. Figuras visibles de esta tendencia eran Carlos Drummond de Andrade, Jorge Amado, Graciliano Ramos, entre otros. Sin embargo, ya hacia los años 40 comienza una búsqueda de renovación de la ficción brasileña. Dos autores que se consideran voces innovadoras en este momento son João Guimarães Rosa y Clarice Lispector (VILLARINO, 2006, p. 83). Ya con sus primeras publicaciones, Lispector adquiere, como afirma Carmen Villarino, la "fama de escritora introspectiva y difícil, misteriosa y reservada, de autora hermética con pocos lectores" (p. 84). Así, Lispector aparece desligada de la tendencia dominante del "realismo regionalista del nordeste". (PAMPÍN, 2009, p. 136)

Las características de La pasión según G.H., que abordo en este trabajo, tales como la forma narrativa de la introspección, los planteamientos filosóficos que se pueden colegir de dicha introspección y el hecho de que G.H. sea una mujer consciente de su feminidad son elementos que, aunados con las otras novelas de Lispector, han producido, dentro de la crítica literaria, varias líneas de estudio: una dedicada al análisis del lenguaje y las formas narrativas, una segunda dedicada al estudio del punto de vista femenino y una tercera dedicada al abordaje filosófico de los textos (FERREIRA, 2007). Con respecto a esta última dimensión, es conocido el trabajo del filósofo y crítico literario brasileño Benedito Nunes (1929-2011). $\mathrm{Su}$ estudio tiende a establecer conexiones entre los temas clariceanos y los temas de la filosofía existencialista de Sartre y Camus (LINDSTROM, 1989, p. 23). Dentro de sus planteamientos, identifica que en La pasión, un despojo de lo personal en G.H. neutraliza la diferencia entre lo masculino y lo femenino, absorbida en una condición humana general en contraste con la animalidad y la vida orgánica (NUNES, 1988, p. 29, traducción mía).

Desde los años 70, también ha habido interés en estudiar las figuras de animales dentro del trabajo de Lispector. Algunas veces estos análisis han tenido un tono existencialista y otras veces un tono más social y ético. Hoy en día, esa línea de investigación se ha fortalecido con el auge del giro animal, que se centra en la exploración de las relaciones entre humanos y animales. Para referirse a estas relaciones dentro de la literatura, la profesora 
Patrícia Vieira (2018, p. 63) acuñó el término zoophytographia. Con este término, Vieira describe la presencia de plantas y animales en el trabajo de Lispector y lo relaciona con el proceso de escritura. Menciono el giro animal, porque, como veremos más adelante, me interesa la manera en la que G.H. vincula lo animal y lo no humano al proceso de definir qué significa ser una persona.

Este trabajo busca continuar la mirada filosófica sobre La pasión teniendo en cuenta tanto las preocupaciones de la teoría de los afectos en relación con las potencias del cuerpo, como la pregunta ontológica que atraviesa su obra, qué significa ser, pero con dos variaciones: por un lado, en vez del gesto existencialista del terror frente a la nada, sugiero la pregunta por la nada como un elemento más para comprender la subjetividad y la tendencia clariceana a preguntarse por el despojo de los atributos; por el otro, en vez de la división entre humano y no humano, propongo la inclusión de lo segundo en lo primero, como una propuesta de G.H. para entender de dónde viene su humanidad y qué es lo que eso significa. Esta vía de pensamiento nos acerca a una de las maneras de concebir el afecto por parte de la teoría: distinto de la emoción. Pero, como los afectos son profundamente contextuales (PAPACHARISSI, 2015, p. 13, traducción mía), también hay en en la novela una propuesta sobre las emociones como una manera de narrar la trayectoria a través de la interioridad. La interioridad es el espacio en el que el cuerpo es consciente de sus devenires.

A partir de la idea de que Lispector - y los problemas planteados en La pasión según G.H. - es un antecedente en Latinoamérica de las preguntas que han ocupado a la teoría de los afectos, enfoco el presente trabajo en dos vías de pensamiento sobre el afecto: alejado de la emoción — vía a la que pertenecen estudiosos como Brian Massumi, Gilles Deleuze, Félix Guattari, Patricia Clough, Kathleen Stewart_, o casi como sinónimo de ella — en este corpus podríamos incluir a Sara Ahmed, Ann Cvetkovich y gran parte de estudiosos latinoamericanos que se dedican a la teoría de los afectos en Latinoamérica como Ana Del Sarto, Ana Peluffo, los estudios compilados por Mabel Moraña e Ignacio Sánchez en El lenguaje de las emociones: afecto y cultura en América Latina, los estudios compilados por Ana Abramowski y Santiago Canevaro en Pensar los afectos en América Latina: Aproximaciones desde las ciencias sociales y las humanidades - y los compilados por Cecilia Macón en Pretérito indefinido. Afectos y emociones en las aproximaciones al pasado y Afectos políticos. Ensayos sobre actualidad, con Daniela Losiggio. 
En La pasión según G.H. se abordan las dos vertientes, que ilustro con los siguientes fragmentos. Con respecto a la primera vertiente, G.H. reflexiona sobre “...lo no humano es el centro irradiante de un amor neutro en ondas hertzianas" (LISPECTOR, 2001, p. 150). Con respecto a la segunda, G.H solo puede imaginarse "pensando y sintiendo, dos atributos de ser" (p. 151). Considero que las dos posturas apuntan tanto a la reflexión sobre qué significa un cuerpo vivo y cuáles son sus potencias, como a los impactos que producen los cuerpos entre sí y que se comprenden a través de las emociones. En el primer apartado de este trabajo, "Las ondas hertzianas: La búsqueda de lo impersonal", planteo el tema de la vida en sí misma, lo "neutro" (impersonal) de los afectos como una manera de leer la búsqueda sobre qué significa ser. En el segundo apartado, "Pensar y sentir: Las emociones como narrativa del ser", abordo el asco y el amor como mediadores del reconocimiento de la subjetividad y del encuentro con lo otro (humano o no humano).

\section{1) Las ondas hertzianas: la búsqueda de lo impersonal}

En La pasión según G.H. - título que, de entrada, nos propone una definición individual e introspectiva sobre los afectos — - la búsqueda de qué es ser responde a la necesidad de comprender qué significa la vida y dónde mora la humanidad como una de las formas de lo vital. Con la idea de que Lispector aborda las preocupaciones sobre el afecto como fuerza que nos ayuda a comprender las potencias del cuerpo - línea de pensamiento que nos remite hasta Baruch Spinoza — , abordo en esta sección una de las acepciones de la afectividad propuestas, entre otros estudiosos, por el filósofo canadiense Brian Massumi: autónomo, independiente del lenguaje, de la percepción consciente y de la emoción (CLOUG, 2010, p. 209). En este sentido, el interés de Massumi es pensar el afecto en términos de lo virtual, es decir, de la potencia (p. 209).

“La vida más profunda está antes de lo humano" (LISPECTOR, 2001, p. 117). Esta es una de las sentencias que nos permite pensar que en Lispector ya hay una preocupación similar a la de pensar el afecto como una intensidad que es asocial, porque existe antes de la forma individual. Esas son las profundidades que navega G.H. en la búsqueda de dónde mora lo humano. Si en términos generales la teoría de los afectos estudia la capacidad — la potencia - de los cuerpos de afectar y ser afectados (CLOUGH y HALLEY, 2007, p. 2, 
traducción mía), es clave pensar en qué sucede, en la obra clariceana, con la construcción de la subjetividad en medio de estas capacidades o potencias.

De esta vía de pensamiento que separa afecto de emoción, considero iluminadores tres asuntos: pensar la potencia de los cuerpos no en un sentido patriarcal, sino en el sentido spinoziano de la posibilidad; pensar que si el devenir no-humano es producto de una proximidad con otras formas de lo vital material, la intimidad, que es en la que "ocurre" la introspección, podría ser o permitir devenires; por último, la localización del contacto entre cuerpos en la vida cotidiana permite repensar entornos tales como el doméstico, que es uno de los espacios que producen mayor intensidad cuando hablamos de proximidades (no siempre armónicas) entre los cuerpos que lo habitan, y sus posibilidades de expansión tanto hacia la destrucción del binarismo público-privado como de la expansión de la familiaridad hacia situaciones que la pongan en entredicho. Los impactos y los efectos que narra G.H. a lo lago de su introspección son, justamente, las verbalizaciones ${ }^{2}$ que logra de la comprensión de las intensidades que produce el contacto entre cuerpos disímiles: una mujer blanca de clase alta, una mujer negra que es la empleada doméstica, un hombre que no existe pero al que se recuerda y se "inventa", una cucaracha y un dibujo en la pared.

No es propio únicamente de La pasión según G.H. la reflexión sobre lo impersonal como semilla de lo vital: en Agua viva (1973), la narradora menciona el it, el misterio de lo impersonal que está dentro del sujeto. De manera que en Lispector intuimos ya una noción no esencialista de lo que es la vida o la subjetividad humana: son soplos de vida. Esta propuesta tanto ética como estética señala una tradición dentro de la teoría de los afectos, representada por Spinoza (filósofo importante dentro de las lecturas de Lispector), Henri Bergson, Gilles Deleuze y Félix Guattari (CLOUGH, 2010, p. 207, traducción mía). La pregunta netamente clariceana es cómo transitar la forma humana que se ha adquirido.

"La trayectoria somos nosotros mismos" (LISPECTOR, 2001, p. 154), dice G.H. Frente a esta epifanía, una de las respuestas a la pregunta sobre qué significa ser es tener una subjetividad nómada (término de la filósofa italiana Rosi Braidotti). La trayectoria en la que se mueve el sujeto que busca desentrañarse se forma en medio de dos polos: la

\footnotetext{
${ }^{2}$ La narración de G.H. responde ya a una relación con el pasado, aunque sea solo un día de diferencia entre la introspección y la narración. En este sentido, la introspección es asocial y autónoma, que es el carácter que Massumi le quiere dar al afecto; y la narración es individual y verbalizada, de manera que hay más posibilidades de pensar el afecto en términos de las emociones que se conocen.
} 
personalización (adquirir el montaje humano) y la despersonalización, que correspondería a experimentar el despojo, el abandono de los sentimientos, la imagen que los otros se han hecho de G.H. en la dimensión social:

Yo era la imagen de lo que no era, y esa imagen del no ser me colmaba por completo: uno de los modos más fuertes de ser es ser negativamente. Como no sabía yo lo que era, entonces 'no ser' era mi acercamiento principal a la verdad: al menos, tenía el otro lado: al menos tenía el ‘no', tenía mi opuesto. (p. 29)

Esta es otra evidencia del diálogo entre Lispector y las teorías contemporáneas de revisión de la subjetividad, que plantean no solo la relación del sujeto consigo mismo y del sujeto con otros, sino también con lo no humano. De hecho, parte de la crítica literaria reciente que ha abordado la obra de Lispector, especialmente la novela que nos ocupa, ha insistido en la relación entre los personajes y la presencia animal:

En estos espacios la identidad humana es puesta en cuestión a través de tres movimientos disolutivos: el replanteamiento de la clásica oposición entre hombre y animal, la invención de una 'perspectiva animal' — que nunca se alcanza completamente - y la búsqueda formal de los umbrales del lenguaje humano. (YELIN, 2008, p. 223)

En el caso de nuestra novela, lo no humano tendría que ver con el acercamiento del sujeto a unos límites que lo despojan de su humanidad. Es necesario habitar el límite entre ser y no ser humano para poder comprender de qué está hecho lo humano, pero el viaje es mucho más largo y experimental. La propuesta estética con la que Lispector respondería a la inclusión de lo no humano en los asuntos de la subjetividad no es únicamente la relación especular entre G.H. y la cucaracha, sino que dentro de lo humano está la huella de lo no humano, de lo que no éramos pero que llegamos a ser, de lo que todavía no somos y del conflicto entre desear trascender o permanecer (LISPECTOR, 2001, p. 72). Esto quiere decir que dentro de lo humano se vive la contradicción, aquello que se le opone y a lo cual es difícil renunciar.

En el texto "The Invention of a Non-Modern World", dedicado a Lispector, William Paulson menciona dicha contradicción: es importante reconocer los modos antitéticos del encuentro con lo no humano en la escritura de la brasileña (2002, p. 210, traducción mía). Menciona, además, que Lispector estaría contando la historia de cuán difícil es renunciar a los extremos, las polaridades a las cuales estamos acostumbrados: la humanización y su opuesto (p. 210). Las imágenes de las que habla G.H. durante su introspección se remontan 
a tiempos casi inmemoriales, por ejemplo civilizaciones que se acaban (LISPECTOR, 2001, p. 57), escombros que ya no sostienen la noción de ciudad entera (así como ella es solo las letras de su nombre en la maleta) pero que recuerdan que ahí hubo una civilización.

El sujeto ha cruzado los límites del conocimiento de sí mismo y esto ha implicado o habitar o intuir la dimensión ¿contraria? de la subjetividad: habría que ser nadie para habitar el vacío. Para reforzar esta idea del vacío que se habita o del vaciamiento de la subjetividad, es iluminador traer a colación la imagen que deja Janair en la pared de la habitación. Es una imagen en la que solo se ven los contornos de un hombre, una mujer y un perro. De entrada, la imagen es problemática porque de alguna manera es la huella de una relación a su vez problemática entre G.H. y la empleada, porque G.H. olvida su rostro y porque se siente objeto del rencor de Janair. Pero lo que me interesa de esta imagen es el asunto de la representación del vacío: Janair se cuida muy bien de dejar solo contornos y ese "vacío" que se dibuja en la pared es una suerte de representación de lo que G.H. está experimentando con respecto al despojo: la desnudez de la figura es la abstracción de todo lo que no es esencial (p. 28). Es quizás esta descripción que hace G.H. luego del impacto que le produce el mural uno de los núcleos de significado de la novela, pues permite pensar, primero, qué es lo esencial y, segundo, que hay que despojarse de ciertas cosas para poder llegar a lo neutro. Esa imagen silenciosa pero que corresponde, al mismo tiempo, a la construcción de un lenguaje que podría contener la imagen de las reflexiones de G.H. con respecto a la personalización y la despersonalización del ser humano, dialoga también con el proceso de desplazamiento que propone Braidotti a través de la subjetividad nómada, desde estructuras fijas hasta el quiebre de estas: "la creatividad es un proceso nómada de la materia realista en el sentido de que implica un desplazamiento activo de formaciones dominantes de la identidad, la memoria y la identificación, para abrirlas a un rugido que se encuentra al otro lado del silencio". (2014, p. 170)

Es sugestiva la imagen del sonido al otro lado del silencio, porque justamente la lectura que estoy abordando de la novela de Lispector es que dentro de la noción de sujeto hay dos caras: el todo y la nada. Para atravesar de una cara a la otra y terminar la exploración, es necesario llegar a los límites del sujeto, hasta la pasión que es pasible de ser soportada. Quizás aquí se va haciendo mucho más evidente el diálogo con la subjetividad nómada porque implica desplazamiento, implica creación e implica una relación con una nada que no 
es que carezca de sentido, sino que, al contrario, está integrada en la noción de subjetividad. El desplazamiento no es hacia la nada como ocaso en un gesto nihilista; la trayectoria es dentro del sujeto que, al mismo tiempo, contiene y carece, pero que se reconoce en su relación con él mismo y con el mundo que habita:

La leche de vaca no brota para nosotros, pero la bebemos. La flor no se hizo para que nosotros la miremos ni para que sintamos su perfume, y la miramos y la olemos. La Vía Láctea no existe para que sepamos de su existencia, pero la conocemos. Y conocemos a Dios y sacamos de él lo que necesitamos. (LISPECTOR, 2001, p. 130)

Se reconoce, no está en el centro, y busca los mecanismos para su devenir. Es justamente en ese proceso de devenir cuando el sujeto toca los límites de la deshumanización, los límites de la nada (p. 17). Hay, además, otra vuelta de tuerca al asunto de la subjetividad: el ser humano ya no es la medida de todas las cosas; el vacío es ahora la medida del sujeto. Un vacío producto de un proceso de despojo “de lo que era para mí el mundo” (p. 139), para poder encontrar lo "neutro" humano, pero cuya búsqueda no instalaría al sujeto en un nuevo centro porque la "verdad" le haya sido revelada, al contrario: la figura del vacío y del desplazamiento permite la continuidad de la trayectoria, porque siempre va a haber afecciones que lancen al sujeto a otra incomodidad (muchos de los personajes en la obra de Lispector están atravesados por dolores y malestares, que son los que disparan la reflexión, el alejamiento del mundo pero la posterior vuelta a él). El vacío sería producto de una conciencia no dominante que permite el desplazamiento del sujeto entre ser y no ser, entre reconocerse y no reconocerse, entre crear la imagen del vacío para poder entrar y crearse.

Dentro de la novela, se diría que el ser humano es una "especie" de ser humano, porque es incompleto, contradictorio, deshumanizado, incluso monstruoso, y que está compuesto por añadidos como el deseo por la belleza (p. 132), por querer ser humano (p. 137), por la avidez del mundo y por el mismo yo (p. 152). En medio de estas desposesiones de lo que serían solo añadidos, el sujeto emprende el camino hacia la búsqueda de lo neutro, de aquello donde estaría el "núcleo y la simiente de vida" (LISPECTOR, 2010, p. 23) de lo humano. Emprende el camino hacia la despersonalización, que se ha leído como un encuentro con el misticismo, pero que yo pretendo abordar aquí como la búsqueda de G.H. de lo vital en un terreno inmanente: para llegar a lo "neutro" de la vida, al it, que sería la correspondencia de lo neutro despersonalizado en su novela Agua viva, habría que despojarse de aquello que ella considera artificial o inútil (los "añadidos" que menciono antes) y de las 
imágenes que otros han hecho de su propia persona. Vale la pena transcribir el fragmento en el que se construye la imagen del camino hacia el despojo, lo que va trazando la llegada a la revelación:

La despersonalización como la destitución de lo individual inútil, la pérdida de todo lo que se puede perder, y aún así, ser. Poco a poco extirpar de uno, con un esfuerzo tan atento que no se siente el dolor, extirpar de uno, como quien se libra de la propia piel, las características. Todo lo que me caracteriza es solamente el modo como soy más fácilmente visible a los demás y como termino siendo superficialmente reconocible por mí. (LISPECTOR, 2001, p. 152)

Lo que se ha puesto de manifiesto hasta ahora con el desplazamiento del sujeto nómada en una trayectoria interior, es decir, con el recorrido que hace el sujeto desde su malestar profundo, su revisión de los afectos y su pregunta sobre dónde está lo humano (que, en otras palabras, es la pregunta por quién es, por el reconocimiento), es la deconstrucción de una subjetividad fija, entera, de una sola cara. Así, las relaciones del sujeto consigo mismo y con el mundo que habita están atravesadas, según Giorgio Agamben, no por la luz ni la apertura al conocimiento, sino por sus opuestos: la opacidad y la clausura. (2007, p. 405)

He querido mencionar que G.H., después de su malestar profundo, inicia un proceso de reflexión que va a significar el repaso de su vida afectiva, esto es, el repaso de aquello que la ha afectado a ella y de acciones con las que ella ha afectado a los demás. ¿Con qué se encuentra? Por un lado, con los sentimientos, lo que implica que ha sido consciente de la relación con ella misma y de la relación con otros (especialmente, con Janair y con el interlocutor ausente); por el otro lado, con lo no humano, es decir, con la necesidad de despojarse de su "montaje humano" para ver si logra comprender qué es lo que habría en ese montaje, de qué puede prescindir y qué hacer después de la comprensión. De esta manera, el hecho de que la subjetividad de G.H. esté personificada, integrada a algo y situada habla de su lugar de enunciación (mujer, artista, clase alta, proveniente de clase baja, que abortó, que tuvo una ruptura amorosa y todas las demás características que conocemos de G.H. a lo largo de su propia voz), mas no de la imposibilidad de devenir otra y de volver al mundo exterior con una nueva manera de relacionarse. En La pasión según G.H. no hay una intención de centrar a la protagonista, justamente lo contrario: no se trata de narrar el hallazgo, sino la búsqueda, extenderse “más allá de la sensibilidad”. (LISPECTOR, 2001, p. 157) 


\section{2) Pensar y sentir: las emociones como narrativa del ser}

La narración de G.H. remite, casi en simultánea, al pasado de la introspección: ayer perdí mi montaje humano. La intuición de lo neutro - que puede ser lo monstruoso, lo animal o una fuerza vital, materia prima, un plasma seco - se convierte en la narración de lo afectivo: si bien "todo sucede por encima o por debajo del dolor" (LISPECTOR, 2001, p. 103), el dolor es el referente, la vara con la que se mide, la sensación con la que se comprende la humanidad. Hay dos afectos clave para la comprensión de la introspección de G.H.: la repugnancia y el amor. El primero genera la introspección y el cuestionamiento: "[...] antes de entrar en la habitación, ¿qué era yo? Era lo que los demás siempre me habían visto ser, y así me conocía yo" (p. 22); el segundo, la sostiene: "necesito aferrarme a esta mano tuya" (p. 17).

El texto The Cultural Politics of Emotion, de Sarah Ahmed, plantea lo que considero que es más importante en la consideración del afecto como elemento teórico: sin la necesidad de hacer una diferencia tajante entre afecto y emoción, Ahmed considera las emociones como las reacciones con las que respondemos a objetos o a otros sujetos $(2014$, p. 10, traducción mía). Lo interesante de este planteamiento es que permite pensar en la historización y la interseccionalidad (relaciones de género, clase y raza) de las emociones: quienes reaccionan son sujetos que pertenecen a contextos particulares, no son abstractos. Ahmed menciona, también, las impresiones para crear el campo semántico de los afectos. Al hablar de impresiones permite solucionar binarismos y superar la idea de que las emociones, las sensaciones y el pensamiento corresponden a dimensiones distintas (p. 28): pensar y sentir son dos atributos de ser, dice G.H.

Dentro de esta mirada crítica, se han incluido los sentimientos como objeto de preguntas investigativas académicas. Ann Cvetkovich define afectos y sentimientos como términos o categorías genéricas, de naturaleza somática o sensorial, que van más allá de ser meros conceptos cognitivos o construcciones (2014, p. 4, traducción mía). Esta definición será fundamental para comprender la vivencia de los afectos en la vida cotidiana, el nomadismo ontológico de G.H. y la búsqueda de comprensión de sí misma, porque "conecta a los sentimientos con una historia de las emociones, con la relación entre el espacio público y el espacio privado, la construcción de la interioridad, la subjetividad y la vida íntima” (2014, p. 8, traducción mía). Estos temas son fundamentales en la introspección de G.H., quien se convierte en sujeto nómada de su propia existencia en la búsqueda de su fundamento 
ontológico. Si durante la introspección el sujeto se encuentra con contradicciones, las organizará, de alguna manera, en el momento en el que conciba la necesidad de expresarlas a un interlocutor. En ese sentido, G.H. construye una especie de umbral en el que se ubica en medio de dos dimensiones: la solipsista y la relación con el otro.

Dentro de la tradición literaria brasileña, Lispector representa un giro íntimo. Esta categoría tiene varias aristas sobre las que hay que detenerse. En primer lugar, es un término acuñado para reconocer cómo los relatos íntimos de tinte etnográfico o autoetnográfico pueden hacer parte como contenido y como metodología en la investigación en las humanidades (para ello, ver el texto Writing Intimacy into Feminist Geography, editado por Pamela Moss y Courtney Donovan). En segundo lugar, caracteriza la obra de Lispector como un punto de fuga con respecto a los intereses del canon: de las reflexiones sobre problemas sociales se pasa a una consideración sobre el individuo, aunque esto no significa, de ninguna manera, que haya una abstracción sobre lo humano, sino que hay un interés por pensar el lugar en el mundo desde la intimidad. En tercer lugar, en La pasión según G.H., puede considerarse la intimidad como un campo de fuerzas -el género, la clase, la raza, los afectos - en el que el sujeto construye su subjetividad (OSORIO, 2020, p. 30) o la pone en tensión entre ser y no ser, como es el caso de G.H., entre ser un monstruo y ser humano, entre el todo y la nada, entre el cuerpo y el vacío, entre el montaje humano y el "it", el soplo de vida, lo impersonal.

Las relaciones entre los sujetos, que también ocurren en la intimidad de la casa y de la interioridad de G.H., existen en las palabras, es decir, son mundos creados y mediados a través del lenguaje, aunque ese lenguaje también fracase, pues no conduce a rotundas "esencias" o certezas absolutas:

Poseo a medida que designo; y éste es el esplendor de tener un lenguaje. Pero poseo mucho más en la medida que no consigo designar. La realidad es la materia prima, el lenguaje es el modo como voy a buscarla, y como no la encuentro. Pero del buscar y no del hallar nace lo que yo no conocía, y que instantáneamente reconozco. El lenguaje es mi esfuerzo humano. (...) Lo indecible me será dado solo a través del lenguaje. (LISPECTOR, 2001, p.154)

Tres características fundamentales hay en la necesidad de comunicación: el interlocutor es creado, no responde; a lo que accedemos es a las huellas - afectos - que ese interlocutor ha dejado en la protagonista; y no es un personaje completo (igual que G.H., 
como veremos), G.H. solo imagina sosteniendo su mano. Aquí ya tenemos otro pliegue de la subjetividad de G.H.: los otros son necesarios para el devenir, pero esos otros solo existen como creación, en el caso del interlocutor inventado, silencioso y fragmentado con el que dialoga G.H., o como recuerdo, que es el caso de Janair, la empleada, de quien solo sabemos aquello que G.H. puede recordar: "su rostro negro y tranquilo" (p.38), la falta de caderas y senos, y los colores de la ropa que llevaba por debajo del delantal, pero que es quien detona la reflexión de G.H. por el malestar que le produce a la dueña de casa el dibujo en la pared, el limpio y organizado imperio que Janair había construido y el no saber si odiaba a Janair o era ella la receptora de su odio. Aquí hay un impacto problemático entre cuerpos y afectos que son contextuales y cuyas potencias responden, justamente, a los lugares geopolíticos de enunciación de cada uno:

Me pregunté si, en verdad Janair, me habría odiado, o si era yo quien, sin haberla siquiera mirado, la odiaba. Tal como ahora estaba descubriendo con irritación que la habitación no dejaba de irritarme; detestaba aquel cubículo que sólo tenía superficies: sus entrañas se habían calcinado. Lo miraba con repugnancia y desaliento. (p.40, las cursivas son mías)

En este fragmento, la deshumanización no tiene que ver con la búsqueda de lo impersonal, sino con la repugnancia con la que se niega la presencia del otro - en este caso, una empleada doméstica negra - o se la carga de un significado adverso: la ira africana, la extranjera, la enemiga (p. 40). La repugnancia está relacionada tanto con la familiaridad como con la extrañeza (p. 134): el otro — que no me es familiar- es el que causa repugnancia, es decir, no es familiar pero lo reconozco como repugnante. La extrañeza es la familiaridad, ocupa el lugar de la intimidad. La intimidad de Janair y la intimidad de G.H. están en discordia. Esta discordia se cifra en la manera de habitar el espacio doméstico, lo que es una manera material de pensar cómo se habita el espacio interior y cuáles son las marcas que los otros dejan en uno. En el relato, la intimidad de Janair prevalece en el afecto de G.H. La de G.H. habrá de reconstruirse, pero para ello necesita otro más cercano a ella.

¿Qué es lo que promueve la presencia del interlocutor creado? Tanto la "presencia" de Janair — son necesarias las comillas, pues solo existe en la impresión de G.H. y en la silueta que deja en el cuarto- como la necesidad de crear al interlocutor dan cuenta de lo que sucede con la proximidad de los cuerpos: la potencia de la afectación y en la introspección como performance política de los encuentros íntimos (íntima es la relación con Janair, por la cercanía espacial doméstica y por la sospecha del odio, e íntima es la relación 
con el interlocutor a través del amor como afecto que los une):

[...] cada uno de estos modos retóricos está conformado por las formas en que una subjetividad evoca a otras de modo que, en una interpretación de intersubjetividad fantasmagórica, el escritor adquiere una autoridad sobrehumana de observación, lo que permite la posibilidad de una performance del ser por la proximidad del objeto. (BERLANT, 2010, p. 95, traducción mía)

En una lectura sobre G.H. no se hablaría de autoridad sobrehumana, justamente porque su trayectoria introspectiva apunta a la desjerarquización de las formas de vida — de ahí que sea tan importante el impacto de la cucaracha y que sea posible la interpretación de que G.H. deviene cucaracha (aunque a mí me interesa la inclusión de lo no humano dentro de lo humano, más que la "metamorfosis") — - La introspección compartida produce varios efectos. Primero, descubrir que ser es estar lleno de palabras. Segundo, encontrar una manera de darle sentido a las reflexiones sobre sí misma, lanzándola a una dimensión compartida, no solipsista. Esto dota a la intimidad de un tinte político, pues pone en evidencia las proximidades políticas entre los cuerpos: los asuntos de género, clase y raza — especialmente esta última con la relación problemática con Janair- Tercero, permitir el cuestionamiento de la subjetividad, porque incluye, nuevamente, el afecto como una manera de acceder a la conciencia de sí, y porque ese "sí" del que se está consciente es tanto fragmentado como limítrofe de algo mayor, la nada:

Por el momento, necesito aferrarme a esta mano tuya, aunque no consiga inventar tu rostro, ni tus ojos, ni tu boca. Pero, aunque mutilada, esta mano no me asusta. Su invención procede de tal idea de amor, como si la mano estuviese realmente sujeta a un cuerpo que, si no veo, es por incapacidad de amar más. No estoy en situación de imaginar a una persona entera porque no soy una persona entera. (LISPECTOR, 2001, p. 17)

Como estamos frente a una persona no-entera (porque está despojándose de aquello que ha creído ser y de la manera en la que el exterior la ha definido, porque de ella solo conocemos las iniciales de su nombre, ni siquiera su nombre completo, y porque ella se reconoce a sí misma como tal) que está relacionándose, únicamente a través del lenguaje, con otro personaje no-entero (solo siente su mano), el marco afectivo se quiebra también, y entonces accedemos a definiciones contradictorias de los afectos y a la necesidad de acudir a otras experiencias sensoriales con las que se pueda describir ese marco en el que se desenvuelve la comunicación: el amor-tejido, que es en el que se entrelazan los que se aman 
(p. 77); el amor-tedio, que sería la eternidad del amor (p. 135) y, sobre todo, el amor inherente, tan importante con respecto a la pregunta sobre lo humano, ¿si es inherente, en el amor mora lo humano? El quiebre del marco afectivo y de las contradicciones de los afectos tiene que ver también con una revisión del mismo término, como, según Cvetkovich, la idea de que las mujeres son naturalmente más emocionales que los hombres o que la emoción es siempre liberadora (2014, p. 8, traducción mía), y con su inclusión en el ámbito académico en relación con la historia de las emociones, la relación entre lo público y lo privado, y la construcción de la interioridad, la subjetividad y la vida íntima (ibid).

Si lo que potencia la reflexión es un hecho cotidiano, el día a día, o la ruptura de la cotidianidad (pues G.H. hace un "alto" en sus actividades cotidianas durante el día introspectivo que se narra en la novela), aquí se incluyen el amor (que es polisémico por las varias categorizaciones que tiene), los sentimientos (que son contradictorios) y la vida íntima (el encierro de G.H. y sus reflexiones interiores, solitarias), como potencia del sujeto, es decir, como factores que permiten el descubrimiento de la capacidad para organizar la experiencia y que lo hacen en relación con la intensidad de los afectos, el nivel de identificación y el nivel de transformación que logra el sujeto que se mira a sí mismo. Parafraseando a Kathleen Stewart (2007, p. 3), la importancia de la presencia de los afectos radica en las reflexiones que posibilitan y en los modos potenciales de conocer, relacionar y atender a las cosas, lo que ya está de alguna manera presente en ellos en un estado de potencia y resonancia.

Importante la mención de la potencia y la resonancia, porque aquí se tiende un puente entre el afecto como potencia y la noción de subjetividad de Agamben anclada en lo real. Según el filósofo, el sujeto se enfrenta a "la experiencia quizá más exigente — y no obstante ineludible - con que le es dado medirse: la experiencia de la potencia" (2007, p. 352), es decir, el yo puedo, "que no se refiere a ninguna certeza ni a ninguna capacidad específica, y que sin embargo lo empeña y lo pone completamente en juego"3 (p. 352). En síntesis, los

\footnotetext{
${ }^{3}$ Entiendo la noción de potencia de Agamben, no como evidencia del hombre que todo lo puede, sino justamente como una posibilidad del ser humano de encontrarse cara a cara consigo mismo, con sus conflictos (como los de G.H. en su búsqueda de qué significa ser) y con la posibilidad (o no) de establecer relaciones con otros en un plano ético. Justamente en esta dimensión ética plantearé los descubrimientos de G.H. en torno a las relaciones con otros en el plano afectivo. Una consideración más sobre la potencia de Agamben: es significativo que la reflexión del filósofo sobre cómo el sujeto se pone en juego frente al enunciado "yo puedo" parte de una anécdota relacionada con el lenguaje poético: el origen del libro de poemas Requiem de la poeta rusa Ana Ajmátova. En una fila, esperando tener noticias sobre su hijo, preso por delitos políticos, una mujer
} 
afectos son la potencia y la vía creadora del sujeto, independientemente de sus contradicciones (o por causa de ellas, ya que el malestar de G.H. hace que inicie la búsqueda de sí misma y, a su vez, esa búsqueda le produce dolor). A través de la capacidad de afectar y ser afectada, G.H. puede remitirse a los afectos para definirse a sí misma: yo soy. O, por lo menos, preguntárselo: ¿qué soy? Hay una pregunta directa por lo personal y por la manera en la que el sujeto se comporta dentro de la esfera privada y, más aún, de la esfera íntima.

\section{Conclusões}

¿Cómo, entonces, inaugurar en mí la reflexión? Y tal vez sólo la reflexión me salvase: temo la pasión. (LISPECTOR, 2001, p.14)

La introspección es una performance política: es la conciencia sobre el espaciotiempo que se habita, sobre el lenguaje que se usa, sobre el campo geopolítico de fuerzas en el que se construye la intimidad y sobre el lugar que se le da a otros. La inclusión, dentro de la teoría de los afectos, de las preguntas por lo que un cuerpo puede hacer (heredada de Spinoza), de lo preindividual y lo individual, y de las "emociones como contenidos subjetivos" (MASSUMI, 1995, p. , la traducción es mía) son maneras de preguntarse cómo los cuerpos habitan e impactan el espacio en los que se relacionan, especialmente cuando esos espacios pertenecen al dominio — no puro ni solipsista — de lo íntimo, que está cargado afectivamente. En otras palabras, la introspección es una manera de construir un relato de las micropolíticas de los cuerpos, los territorios y los afectos ${ }^{4}$.

Frente a la introspección de G.H. y el ir y venir entre sus reflexiones sobre la personalización y la despersonalización como dos caras de la misma moneda, surge la pregunta sobre cuál es el tipo de subjetividad que plantea los límites entre la afirmación y la negación. La presencia de dos polos traza un camino que puede recorrerse. Ahí es donde la

le preguntó: “¿puede usted decir esto?”, a lo que la poeta respondió: “sí, puedo” (AGAMBEN, 2007, p. 352). La importancia de la anécdota radica en que nos lanza a la dimensión del sujeto "vulnerable" (mujer, madre de preso político) frente a la capacidad de nombrar, es decir, de tener la posibilidad del lenguaje; más aún: tiene la posibilidad del lenguaje poético.

${ }^{4}$ Esta tríada hace parte de una relación que establece la scholar Montserrat Madariaga (The University of Texas at Austin), inspirada en las teorías desarrolladas por Kim TallBear, Silvia Rivera Cusicanqui y la comunidad de historia mapuche. 
noción de subjetividad nómada ilumina la conciencia del sujeto sobre sí mismo a través de su apertura al devenir. La trayectoria del sujeto dentro de sí mismo se potencia por el descubrimiento del miedo a la pasión y el miedo a ser, es decir, por el descubrimiento de la afección. El afecto es parte integral del devenir perpetuo de un cuerpo (siempre volviéndose diferente de lo que es, aunque sutilmente), que está tanto afuera de sí como en sí mismo, hasta que, en última instancia, esa distinción deja de tener relevancia (SEIGWORTH y GREGG, 2010, p. 3, la traducción es mía).

La conciencia de lo exterior, de cómo se habitan los espacios, se incorpora y entonces la pregunta tiene que ver con cómo se habita el espacio interior. Para ser más exactos, la pregunta sería qué es eso que llamamos espacio interior y cuál es el ser que lo habita. Por otro lado, el diálogo con un interlocutor ausente también problematiza la relación con el exterior, porque la existencia de ese interlocutor se evidencia únicamente a través de las huellas dentro de la subjetividad de G.H. Es un exterior interiorizado. Pero, al fin y al cabo, necesario para la creación de una intersubjetividad que permita que el sujeto dialogue y pueda trazar la trayectoria hacia sí mismo.

“¿Qué puede ser un conocimiento que no tiene ya como correlato la apertura al mundo sino solamente la vida y su errancia?" (AGAMBEN, 2007, p. 483). Es posible que el término errancia funcione como una manera de hacer referencia al recorrido del sujeto a través de sí mismo, pero no necesariamente como divagación, sino como nomadismo, como desplazamiento. Este devenir permite intuir qué es ser persona: primero, para poder llegar a la afirmación, pasa por la negación, y es entonces cuando descubre la nada — lo impersonal— como espacio que se habita. Aquí creo que hay un asunto importante en el proyecto estético de Lispector, porque la construcción de los personajes, su malestar, sus dolores y sus introspecciones van llegando al límite incluso de que no se puede sostener una noción completa de personaje, de sujeto, sino que hay que ir fragmentándolo hasta crear uno que sea nadie (Martim, en La manzana en la oscuridad; Macabea, en La hora de la estrella), ir despersonalizándose y, en ese proyecto, encontrar la trayectoria hacia el devenir, hacia la búsqueda constante del secreto humano.

La segunda consideración tiene que ver con qué produce la obra de Lispector al lado de corrientes teóricas contemporáneas que piensan las potencias políticas y estéticas del afecto. Pienso que es posible que la construcción epistemológica que hace Lispector vaya en 
dos vías: por un lado, el vuelco hacia lo personal, aislado, como otra manera de entender al sujeto. Esto implicaría volver problemática la relación entre la dimensión pública y la dimensión privada: ¿cuáles son los puntos de encuentro y de desencuentro entre el reconocimiento que hacen los otros del sujeto, el reconocimiento que hace el sujeto de sí mismo cuando está con otros y el reconocimiento que hace el sujeto de sí mismo en aislamiento (al menos, espacial)?

Por el otro lado, incluye la vida doméstica y la intimidad, no solo como mapas que duplican las disparidades sociales entre las clases y las razas (en la novela, G.H. tiene prejuicios con respecto al modus vivendi de Janair por el hecho de ser una empleada doméstica, y el espacio que ocupa dentro de la casa es marginal), sino como dimensiones en las que el sujeto también descubre su propio descentramiento hasta reconocer que no es la medida de todas las cosas ni el parámetro de todas las relaciones con el mundo: "No el acto máximo, como antes había pensado, no el heroísmo y la santidad. Sino por fin el acto ínfimo que siempre me había faltado. Siempre había sido incapaz del acto ínfimo. Y como el acto ínfimo, me había desheroizado" (LISPECTOR, 2001, p. 153). Si las corrientes de pensamiento contemporáneas están inscritas en la definición de subjetividades políticas tales como las feministas, por ejemplo, una lectura contemporánea de Lispector haría eco de dichos surgimientos a través del reconocimiento del valor del individuo, de la intimidad como espacio en el que también se construye un lenguaje (aunque este sea deficiente) para autorrepresentarse y, por ende, del planteamiento de una subjetividad que descubre que está descentrada.

El gesto transgresor de G.H. es reconocer la existencia de un ethos afectivo, es decir, la posibilidad ("yo puedo" de Agamben) y la voluntad de acercarse al otro (humano o no humano, de una manera desheroizada, descentrada, sin jerarquías) y al mundo, a través de las pulsiones vitales, que podría ser un rasgo de lo humano. Este ethos solo puede reconocerse en la intimidad del espacio interior y en la intimidad de la relación afectiva (por eso es necesaria tanto la presencia de Janair, una afectividad "negativa", como la del interlocutor ausente, una afectividad "positiva"), lejos de las miradas que quieren configurar y encasillar al sujeto para convertirlo en objeto de relación:

La despersonalización como la destitución de lo individual inútil, la pérdida de todo lo que se puede perder y, aún así, ser (...) Todo lo que me caracteriza es solamente el modo como soy más fácilmente visible a los 
demás y como termino siendo superficialmente reconocible por mí. (2001, p. 152)

En ese sentido, se adquiere una noción de encuentro con el otro mucho más atenta a las afecciones: si bien el solipsismo permitió la concentración de G.H. en sí, el producto de ese solipsismo es la comprensión, entre otras cosas, del encuentro con el otro en el eros. Ella alcanza a salir de sí misma, aunque la comprensión de la interioridad sea borrosa o se contemple irrepetible: "Por fin me extendía más allá de mi sensibilidad. (...) Nunca más comprenderé lo que diga. Pues ¿cómo podré hablar sin que la palabra mienta por mí? ¿Cómo podré decir, sino tímidamente: la vida me es? (...) Y entonces adoro...” (2001, p. 157). El gesto final, aprendido en la intimidad del encierro, es profundamente público, porque le abre espacio a otro, humano o no humano. El gesto final, que es con el que termina la novela, es hacer visible el terreno de los afectos: adorar.

\section{Referencias}

ABRAMOWSKI, Ana y CANEVARO, Santiago. Introducción. Pensar los afectos: Aproximaciones desde las ciencias sociales y las humanidades. Buenos Aires: Ediciones UNGS, 2017, pp. 9-26.

AHMED, Sarah. The Cultural Politics of Emotion. Edimburgo: Edinburgh UP, 2014.

AGAMBEN, Giorgio. La potencia del pensamiento. Traducido por Flavia Costa y Edgardo Castro, Argentina: Adriana Hidalgo, 2007.

BERLANT, Lauren. Cruel Optimism. En: SEIGWORTH, Gregory y GREG, Melissa.

(ed.) The Affect Theory Reader. Durham: Duke University Press, 2010, pp. 93-117.

BRAIDOTTI, Rosi. Writing as a Nomadic Subject. Comparative Critical Studies, vol. 11, issue 2-3, 2014, pp. 163-84, doi: dx.doi.org/10.3366/ccs.2014.0122

CLOUGH, Patricia Ticineto y HALLEY, Jean. The Affective Turn: Theorizing the Social. Durham: Duke University Press, 2007.

CLOUGH, Patricia Ticineto. The Affective Turn: Political Economy, Biomedia, and Bodies. En: SEIGWORTH, Gregory y GREG, Melissa. (ed.) The Affect Theory Reader. Durham: Duke University Press, 2010, pp. 206-225. 
CVETKOVICH, Ann. Introduction. Depression: A Public Feeling. Durham: Duke University Press, 2014, pp. 1-26.

DEL SARTO Del Sarto, Ana. Los afectos en los estudios culturales latinoamericanos. Cuerpos y subjetividades en Ciudad Juárez. Cuadernos de literatura, no. 32, Julio Diciembre 2012, pp. 41-68., http://revistas.javeriana.edu.co/index.php/cualit/article/view/4060

FERREIRA, Cristina. Clarice Lispector e a crítica. Clarice Lispector: novos aportes críticos. U of Pittsburgh, 2007, pp.7-23, www.hispanic.pitt.edu/iili/IntroLispector.pdf

LISPECTOR, Clarice. La pasión según G.H., Traducido por Alberto Villalba, Barcelona: Muchnik Editores, 2001.

LINDSTROM, Naomi. Clarice Lispector: Articulating Women's Experience. Women's Voice in Latin American Literature. Three Continents P, 1989, pp. 23-45.

MASSUMI, Brian. The Autonomy of Affect. Cultural Critique, no. 31, 1995, pp. 83-109, JSTOR, www.jstor.org/stable/1354446

NUNES, Benedito, coordinador. Introdução do coordenador. A paixão segundo G.H. Edição crítica. Brasil: Editora da UFSC, 1988, pp. xxiv-xxxiii.

PAMPÍN, María Fernanda. La explosión del folletín en La hora de la estrella. El matadero, 2009, No. 6, pp. 136-145.

PAPACHARISSI, Zizi. The Present Affect. Affective Publics. Sentiment, Technology, and Politics. Nueva York: Oxford University Press, 2015, pp. 6-29.

PAULSON, William. The Invention of a Non-Modern World. En: PAZOS, Cláudia y WILliAMS, Claire (ed). Closer to the Wild Heart. Essays on Clarice Lispector. Oxford: Legenda, 2002, pp. 198-212.

SEIGWORTH, Gregory y GREG, Melissa, editores. An Inventory of Shimmers. The Affect Theory Reader. Durham: Duke University Press, 2010, pp. 1-25.

STEWART, Kathleen. Ordinary Affects. Durham: Duke University Press, 2007. VIEIRA, Patrícia. Zoophytographia: Interspecies Literature and the Writings of Clarice Lispector. States of Grace. Nueva York: SUNY Press, 2018, pp. 63-108.

VILLARINO, M. Carmen. Dinámicas y líneas de fuerza en el interior del sistema literario brasileño durante el siglo XX. In: Revista de cultura brasileña, No. 4, 2006, pp. 71-99. 
YELIN, Julieta. Viajes a ninguna parte. Sobre la representación de la animalidad en 'Meu tio o iauaretê' de João Guimarães Rosa y A paixão segundo G.H. de Clarice Lispector. Itinerarios, vol. 8, 2008, pp. 223-33, itinerarios.uw.edu.pl/wpcontent/uploads/2014/12/11_yelin.pdf

\section{CLARICE LISPECTOR E A TEORIA DOS AFETOS UMA LEITURA DO ROMANCE A PAIXÃO SEGUNDO G.H.}

\section{Resumo}

O romance A paixão segundo G.H. pode ser lido como um antecedente da teoria dos afetos na America Latina. Já nos anos 60, Clarice Lispector estava expondo assuntos que a academia estudava com o nome de affective turn: a questão das emoções, do corpo, da materialidade e a vitalidade, a divisão entre emoção e ração, a diferença entre afeto e emoção, a relação com o não-humano, entre outras questões.

\section{Palavras-chave}

Teoria dos afetos. Intimidade. Subjetividade. Lispector. 